\title{
Violência Juvenil e Medidas Socioeducativas: Revisão de Literatura
}

\author{
Jacqueline de Oliveira Moreira ${ }^{1}$ \\ Pontificia Universidade Católica de Minas Gerais \\ Andréa Maris Campos Guerra \\ Carlos Roberto Drawin \\ Universidade Federal de Minas Gerais
}

\begin{abstract}
RESUMO - Neste artigo, partindo do objetivo de compreender a relação entre violência juvenil e a resposta do Estado através das medidas socioeducativas, buscamos explicitar o pano de fundo das pesquisas científicas atuais. Realizamos uma metaanálise dos artigos publicados sobre adolescência e medidas socioeducativas, no campo da psicologia, entre os anos de 2000 e 2012. Concluímos que essa produção nacional pode ser reunida em três grandes categorias: (a) prático-experiencial, que apresenta relatos analíticos da prática na aplicação das medidas socioeducativas, privilegiando a experiência concreta; (b) político-institucional, que discute criticamente a dimensão política da lógica socioeducativa, detendo-se na análise estrutural de sua legislação e de suas instituições; (c) sociocultural, que analisa os determinantes sociais e psíquicos do fenômeno da violência juvenil.
\end{abstract}

Palavras-chave: adolescência, medidas socioeducativas, Estatuto da Criança e do Adolescente, adolescente em conflito com a lei

\section{Juvenile Crime and Socio-educational Measures: A Literature Review}

\begin{abstract}
In this article, which assumes as its main goal to contribute to the understanding of the relationship between juvenile crime and the response of the state through socio-educational measures, we tried to explain the background of current scientific research. We performed a meta-analysis of Brazilian articles on juvenile crime and socio-educational measures in the field of psychology published between 2000 and 2012. We concluded that articles can be divided in three broad categories: (a) practical-experiential, presenting experience reports or technical difficulties in implementing measures, emphasizing concrete experience; (b) political-institutional, discussing critically the political dimension of the logic behind social-educational measures, focusing on a structural analysis of their laws and institutions; (c) sociocultural, analyzing the social and psychological determinants of the phenomenon of juvenile violence.
\end{abstract}

Keywords: adolescence, socioeducative measures, Children and Adolescent Code, teenager in conflict with the law

O tema da criminalidade juvenil convoca diversos setores da sociedade para a reflexão e intervenção. Não poderia ser diferente com a Universidade, que tem por tarefa pensar seu tempo (Santos, 2001). Desde o ano 2008, este grupo de pesquisa interinstitucional se dedica aos estudos do tema da juventude envolvida com a criminalidade violenta. Suas pesquisas e intervenções são resultado de um esforço conjunto com o Estado, através da Secretaria de Estado de Defesa Social de Minas Gerais, e a comunidade, visando à redução dos dados de mortalidade juvenil e violência no país.

$\mathrm{O}$ interesse por esses jovens surge devido ao alto índice de mortalidade juvenil no envolvimento com a criminalidade. O Mapa da Violência no Brasil (Waiselfisz, 2012), conhecido como a "anatomia dos homicídios" no país, confirma esses dados. Em Belo Horizonte, por exemplo, o ano 1997 apresentava uma taxa de 32,6 homicídios a cada 100 mil jovens, passando para 137,1 em 2007.

No último Mapa, verificamos o aumento da mortalidade entre negros na população jovem, comparada à mortalidade entre jovens brancos. Interessante notar que não se observam diferenças significativas de taxas de homicídio entre brancos e negros até

1 Endereço para correspondência: Av. Itau, 525, Bairro Dom Cabral, Belo Horizonte, MG, Brasil. CEP: 30.535-012.E-mail: jackdrawin@ yahoo.com.br os 12 anos de idade. Nesse ponto, inicia-se um duplo processo: por um lado, um íngreme crescimento da violência homicida, tanto branca quanto negra, que se avoluma significativamente até os 20/21 anos de idade das vítimas. Se esse crescimento se observa tanto entre os brancos quanto entre os negros, nesse último caso o incremento é marcadamente mais elevado: entre os 12 e os 21 anos de idade as taxas brancas passam de 1,3 para 37,3 em cada 100 mil, aumenta 29 vezes. Já as taxas negras passam, nesse intervalo, de 2,0 para 89,6, aumentando de 46 vezes. (Waiselfisz, 2012, p. 26)

Partimos, então, para um novo projeto, que foi rastrear na literatura brasileira a produção, no campo da psicologia, sobre adolescentes em conflito com lei e, sobretudo, sobre as medidas socioeducativas. A escolha pelas medidas socioeducativas se justifica pelo fato de que estas expressam a resposta do Estado diante do ato infracional cometido por um adolescente. Sabemos que o Estatuto da Criança e do Adolescente - ECA (Brasil, 1990), que prevê a doutrina de proteção integral, defende a ideia de que a intervenção com o adolescente em conflito com a lei apresente um mecanismo efetivo de reinserção social e de garantia dos direitos. Dessa forma, o sistema propõe seis medidas: advertências, reparo ao dano, prestação de serviço à comunidade, liberdade assistida, semiliberdade e internação. 
A medida de advertência é executada pelo juiz da infância e da juventude. É uma medida imediata e de caráter informativo, em que o juiz, na presença do adolescente e seu responsável, informa-o dos seus deveres perante a lei, do ato cometido e das consequências de uma reincidência (Brasil, 1990).

$\mathrm{Na}$ medida de obrigação de reparação do dano, o adolescente restitui o Estado do bem e/ou visa à compensação da vítima. Também esta é uma medida de caráter informativo que não exige um acompanhamento posterior do adolescente por um responsável técnico pela execução da medida (Brasil, 1990).

A medida socioeducativa de prestação de serviços à comunidade (PSC) busca fazer com que o adolescente responda por seu ato, a partir da realização de um trabalho de prestação de serviço que se dá em sua comunidade. Visa ao resgate dos valores sociais, e o trabalho se inicia com a figura do técnico que acompanhará o adolescente no período de escolha do espaço institucional, desenho da modalidade de trabalho a ser realizado e definição das atividades a serem executadas durante a medida. É importante mencionar que o máximo de tempo de PSC é 6 meses. Assim, a construção do posto de trabalho colabora com o processo de responsabilização frente ao ato cometido (Brasil, 1990).

A medida de liberdade assistida, assim como a de prestação de serviço à comunidade, integra as medidas em meio aberto, ou seja, medidas em que o adolescente não sofre nenhuma sanção à sua liberdade e permanece na sua comunidade e junto à família durante a execução da mesma. Porém, a liberdade assistida visa ao acompanhamento da vida social do adolescente por um técnico durante o cumprimento da medida. Esse acompanhamento busca garantir a proteção do adolescente, sua inserção na comunidade, na escola e na formação para o trabalho, os vínculos familiares e principalmente sua responsabilização frente ao ato infracional cometido (Brasil, 1990).

As medidas mais gravosas previstas são a semiliberdade e a internação. A semiliberdade é restritiva em relação à liberdade de ir e vir, enquanto a internação estabelece uma ação de privação da liberdade. Na semiliberdade, os adolescentes mantêm diversos vínculos externos cotidianamente, como a escola, trabalho e, com frequência, os finais de semana no convívio com os familiares. A medida de internação priva, de maneira bem mais incisiva, o adolescente do convívio externo, pois as possibilidades de saída, restritas, serão construídas ao longo do cumprimento da medida em meio fechado. Ambas as medidas, restritiva e privativa de liberdade, possuem uma proposta de trabalho socioeducativo com base na garantia de direitos, mas também buscam a responsabilização do adolescente frente ao ato cometido como uma das condições para sua extinção em um prazo de até três anos, que é o tempo máximo de sua execução (Brasil, 1990).

Contudo, no contexto das políticas públicas pode-se dizer que o ECA (Brasil, 1990), ao propor as medidas socioeducativas, não legisla sobre as diretrizes de aplicação dessas medidas. Frente à ausência de diretri`zes claras e específicas para a execução das me $\neg$ didas socioeducativas por parte das instituições e profissionais que atuam nessa área, criou-se o Sistema Nacional Socioeducativo (SINASE; lei
12.594/2012), que dispõe sobre os sistemas de atendimento socioeducativo, regulamenta a execução das medidas destinadas ao adolescente, em razão de ato infracional (Brasil, 2012). O SINASE é composto por princípios, regras e ações jurídicas, políticas, financeiras e administrativas, presentes no contexto do trabalho com o adolescente autor de ato infracional, desde a apuração do ato até a execução das seis medidas socioeducativas.

O SINASE fornece as diretrizes e os eixos estratégicos para a execução das medidas socioeducativas de meio aberto e fechado. No entanto, fornecer as diretrizes não é o mesmo que indicar formas de operacionalização do trabalho no cotidiano. É preciso que o trabalho seja realizado e publicado para que possamos reconhecer seus avanços e obstáculos, prosseguindo, dessa forma, na construção de estratégias mais eficientes e éticas. Assim, esperamos que esta pesquisa, que trabalha o estado da arte nacional sobre o tema do adolescente em conflito com a lei, possa contribuir para localizar questões e pensar novas estratégias.

O procedimento metodológico de pesquisa foi o de buscar nos indexadores Scielo e Pepsic a produção científica, no campo da psicologia, sobre o referido tema, com o recorte temporal de 12 anos -2000 a 2012. Cabe ressaltar que esta revisão de literatura foi realizada em janeiro de 2013.

Parece-nos importante mencionar que usamos os termos adolescência, medidas socioeducativas, adolescente em conflito com a lei, ECA, adolescente autor de ato infracional como descritores de busca, sendo que foi possível localizar 59 artigos a partir desses termos. Todos os artigos foram estudados e fichados a partir dos seguintes critérios: ano, estado brasileiro, método (estudos teóricos ou estudos empíricos), problema, hipótese central, principais conceitos, autores de referência, principais ideias e argumentos e, por fim, conclusão ou resultados. A escolha pelo estudo de cada artigo a partir desses critérios expressa a intenção de construir uma categorização dos artigos e, posteriormente, produzir textos sobre cada categoria.

Podemos definir a presente pesquisa como uma pesquisa documental, porque consideramos a produção cientifica na área da psicologia como um documento que revela as posições desse campo de saber diante do tema da adolescência e das medidas socioeducativas. Segundo Laville e Dione (1999), a pesquisa documental em ciências humanas tenta reunir as fontes de informações já existentes sobre o tema investigado. "Resume-se em reunir os documentos, em descrever ou transcrever eventualmente seu conteúdo e talvez em efetuar uma primeira ordenação das informações para selecionar aquelas que parecem pertinentes" (Laville \& Dione, 1999, p.168). Importa, pois, fazer sua triagem, julgar sua qualidade às necessidades da pesquisa, criticá-las e categorizá-las ou codificá-las. Assim, dos 59 artigos lidos, localizamos, no grupo denominado Outros, nove artigos excluídos da análise em função de sua distância em relação à investigação, ora por recrutarem o tema das medidas socioprotetivas (Nascimento, Lacaz, \& Travasso, 2010), ora por focarem temas de muita amplitude, como as múltiplas faces da violência (Silva, 2007) ou o tema da maioridade penal na América latina (Lopez, 2004).

Para realizar essa empreitada investigativa, estivemos atentos aos três obstáculos que Gomes (2001) destaca 
em relação aos riscos da pesquisa social: (a) a ilusão do pesquisador em concluir pelo que lhe é familiar e conhecido; (b) o pesquisador esquecer os significados presentes em seus dados; (c) o pesquisador produzir um distanciamento entre a fundamentação teórica e a prática da pesquisa. Esse cuidado se deu pelo fato de sabermos que toda pesquisa que aborda uma problemática social, mesmo que a partir de uma perspectiva subjetiva, insere-se em um contexto histórico, ideológico e multidisciplinar, exigindo um olhar crítico e transversal. Quando sujeito e objeto possuem a mesma natureza no âmbito da investigação científica, "essa mesma realidade é mais rica que qualquer teoria, qualquer pensamento e qualquer discurso que possamos elaborar sobre ela. Portanto, os códigos das ciências que por sua natureza são sempre referidos e recortados são incapazes de a conter" (Minayo, 2001, p. 15).

Assim advertidos, trabalhamos com a análise de conteúdo, orientada pela construção iterativa de explicação (Laville \& Dione, 1999). A análise partiu da leitura comentada de cada artigo, seguindo categorias como tema, objeto e objetivo do texto, argumentos e conclusão. Procedemos, então, à reestruturação dos conteúdos a partir desses tópicos e, em seguida, recortamos os elementos, ordenados em conformidade com os mesmos. Todos os artigos assim reorganizados foram apresentados e discutidos semanalmente junto ao coletivo da pesquisa para, finalmente, extrairmos sua categorização a partir do modelo de grade aberta, no qual "as categorias não são fixas no início, mas todas tomam forma no curso da própria análise" (Laville \& Dione, 1999, p. 219), chegando às três grandes categorias apresentadas a seguir.

Como se tratava de uma pesquisa exploratória, optamos pela construção iterativa de uma explicação enquanto modelo qualitativo de análise de conteúdo. Nele não se supõe a presença prévia de um ponto de vista teórico, elaborando o pesquisador, pouco a pouco, "uma explicação lógica do fenômeno ou situação estudados, examinando as unidades de sentido, a inter-relação entre elas e entre as categorias em que elas passam, então, a estar inseridas" (Laville \& Dione, 1999, p. 227).

Cabe ressaltar, em nossa investigação, os limites das fontes ou arquivos dos quais decidimos nos valer. Construir o estado da arte nacional sobre o tema da adolescência e infração, partindo inicialmente dos periódicos científicos nacionais reunidos em duas bases digitais, implica um primeiro viés que orienta a tomada de vista de um problema que, sabemos, ultrapassa essa fronteira. Temos conhecimento de que, de saída, essa escolha já constrange nosso objeto de análise, tendo em vista o que se escreveu e publicou em outras fontes, acadêmicas ou não. Não podemos desconsiderar também o desestímulo à produção científica pelos trabalhadores, cotejado com a exigência de produtividade dos professores/ pesquisadores no plano, não apenas nacional, de exigência quantitativa de produção acadêmica. Em razão disso, torna-se impossível não considerar o texto não registrado nas revistas científicas especializadas em nossa análise, posto mesmo que essa pesquisa só aconteceu em função do encontro real entre uma demanda de trabalhadores e a universidade.

Roudinesco (2006), ao tratar do poder arcôntico do arquivo, afirma que seu poder governador e legislador emana de seus próprios limites. Se tudo está arquivado, anotado e julgado, não há possibilidade de criação. Por outro lado, se nada está arquivado, se tudo está apagado e destruído, resta a fantasia ou a soberania delirante do eu. Entre esses dois limites - a interdição do saber absoluto e a interdição da soberania do eu -, o arquivo é a condição da história. Partamos de seus limites como horizonte ético de nossa investigação.

Assim, os dados foram organizados a partir nove critérios (ano, estado brasileiro, método [estudos teóricos ou estudos empíricos], problema, hipótese central, principais conceitos, autores de referência, principais ideias/argumentos, conclusão/resultados). Todas as categorias são importantes na apreensão dos artigos. Todavia, cabe ressaltar que os itens método e problema se mostraram decisivos para realizar a tarefa de categorização. $\mathrm{O}$ item método permitiu perceber que $50 \%$ dos artigos podem ser organizados em torno do eixo estudos empíricos, pois são relatos de experiências (Galo, 2008; Silva, Oliveira, Piccione, \& Lemos, 2008), trabalhos de escuta dos atores envolvidos (Aranzedo \& Souza, 2007; Cella \& Camargo, 2009; Coutinho, Estevam, Araujo, \& Silva 2011) e pesquisas originais (Menucucci \& Carneiro, 2011; Zappe \& Ramos, 2010). Os outros 25 artigos apresentam estudos teóricos, sendo que 16 elegem por problema o estudo da política (Monteiro, 2006), das leis (Alves, Pedroza, Pinho, Presotti, \& Silva, 2009; Brito, 2007; Costa \& Assis, 2006; Sartorio \& Rosa, 2010; Silva, Lemos, \& Melo, 2011; Silveira, 2012) e das instituições (Rosário, 2004; Vicentin, Gramkow, \& Rosa, 2010), e os outros nove apresentam tentativas de pensar determinantes psicossociais para o fenômeno da violência e criminalidade juvenil (Almeida \& Silva, 2004; Costa \& Almeida, 2007; Jost, 2010; Monte, Sampaio, Rosa Filho, \& Barbosa, 2011; Santos \& Zeitoune, 2011; Spagnol, 2005).

\section{Primeiros Resultados: Categorização}

Assim, como primeiro resultado desta revisão de literatura, percebemos que os artigos poderiam ser organizados em três grandes eixos que representam uma tipologia construída a partir de uma ordem de crescente generalidade. Os textos seriam classificados em três planos inter-relacionados: (a) o plano prático-experiencial; (b) o plano político-institucional; (c) o plano teórico-sociocultural. Assim, como estratégia metodológica, optamos por apresentar 1/3 de cada categoria, mas citar todos os artigos encontrados na pesquisa. Temos, portanto uma bibliografia grande, mas conseguimos realizar a tarefa de sumarizar a produção da psicologia na área da adolescência e medidas socioeducativas propondo um dispositivo de leitura da produção atual.

\section{Plano Prático-Experiencial}

Constituído pela coleta e comparação de relatos de experiências concretas e pontuais que são efetivadas em contextos específicos da prática socioeducativa. Definimos esse plano como prático, no sentido clássico de práxis, porque todas as técnicas e formas de intervenção têm algum tipo de motivação ética. A práxis, então, entendida 
como transformação objetiva do processo social, isto é, transformação das relações homem-natureza (práxis produtiva) e homem-homem (práxis revolucionária), é o fundamento do conhecimento, o critério da verdade e a finalidade da teoria. Quanto ao termo experiencial, ele implica a ideia de que a experiência não é uma vivência pura, uma mera reação a algum estímulo, mas traz consigo muitos elementos cognitivos, isto é, interpretações mais ou menos elaboradas de políticas públicas e de hipóteses teóricas. Encontram-se, nesta categoria, 25 artigos, que representam relato de experiência (Costa, Penso, Sudbrack, \& Jacobina, 2011; Rosário, 2010) e pesquisas originais (Jacobina \& Costa, 2007; Kobayashi \& Zane, 2010; Penso \& Sudbrack, 2009; Silva \& Salles, 2011; Sisto, Cecilio-Fernandes, \& Silveira, 2012; Zappe \& Ramos, 2010; Germano \& Bessa, 2010).

O primeiro artigo que encontramos que representa o grupo das reflexões prático-vivenciais é o de Bello (2001). A autora adverte para o risco de o psicólogo, enquanto técnico das medidas, exercer um papel acrítico de mero mandatário e sancionador da lei que coloca o adolescente no mesmo lugar que o senso comum institui: de infrator e de delinquente. É preciso refletir sobre a posição do psicólogo que se encontra entre o adolescente e a justiça, se o profissional assume o lugar de mandatário da justiça, não abre espaço para a escuta do sujeito/adolescente e seu possível reposicionamento na vida. Do outro lado, podemos citar o artigo de Costa (2005), que acena com a possibilidade da atuação do psicólogo representar um "real potencial estruturador da proposta socioeducativa e das possibilidades da ação do psicólogo" (p. 80).

O artigo de Passamani e Rosa (2009) apresenta, usando a metodologia de estudo de caso, a percepção que os operadores da medida socioeducativa de liberdade assistida da Casa Sol Nascente, no estado do Espírito Santo, têm a respeito do seu programa. À medida que relatam as percepções dos profissionais que sustentam o projeto em questão, as autoras fazem sua própria apresentação do mesmo, analisando seus desafios e sucessos. Os profissionais envolvidos com os adolescentes não apresentam uma posição preconceituosa em relação aos mesmos. Todos destacaram que os adolescentes em conflito com a lei "são como todos os demais adolescentes, que têm conflitos, inseguranças, medos. O que pode diferenciar esses adolescentes dos demais, segundo os entrevistados, é que tiveram menos oportunidades" (p. 340). Fundamentados na proposta da pedagogia de Paulo Freire, os atores do processo têm como premissa que cada um tem sua história e valores, fazendose necessário respeitar e realizar o trabalho reconhecendo e acolhendo essas histórias, que, entretanto, convergem para um ponto comum. Segundo as autoras, os adolescentes têm, em geral, uma "história familiar em que há baixos níveis de afeto, pouca coesão e ausência de monitoramento das atividades dos filhos e indiferença generalizada nas relações interpessoais" (p. 333). Esse ponto comum é tomado como o desafio para os profissionais que visam fortalecer as redes de apoio familiar.

O trabalho de Silva et al. (2008) também se fundamenta na pedagogia libertária de Paulo Freire, mas, neste caso, o veículo de intervenção e diálogo com os adolescentes é o futebol. Considerando que as regras do jogo no campo de futebol se diferem daquelas que regem o campo da criminalidade, os técnicos acreditam que o esporte é um instrumento socioeducativo. Assim, apresentam um trabalho bem-sucedido de intervenção nas medidas com adolescentes inseridos em meio aberto, executado em São Paulo, e apostam na possibilidade de ampliar o projeto.

Barra (2007) apresenta uma intervenção realizada no ambulatório oferecido a adolescentes que cometeram delitos e que fazem uso ou abusam de drogas no Rio de Janeiro. Trata-se de uma intervenção orientada pela psicanálise freudiana e lacaniana. Assim, a analista, orientada pela ética da psicanálise, visa a fazer advir o sujeito dividido lá onde havia um saber inconsciente, através da escuta. A autora conclui que o movimento da intervenção deve acontecer com vistas a tentar construir a responsabilização subjetiva que, nas palavras da autora, "sem dúvida, é muito mais implacável e rigorosa do que aquela cobrada pela justiça” (p. 80).

Sustentado na escuta clínica, mas em outra modalidade teórica, podemos citar a intervenção de Perfeito (2005), na qual, a partir do atendimento psicoterápico de base comportamental com adolescentes privados de liberdade, sustenta a importância do vínculo entre adolescente e técnico como forma de romper com a lógica do controle via relatório. Outra modalidade de escuta é apresentada por Costa, Carvalho e Wentzel (2009) por meio da ideia do plantão psicológico que escuta e acolhe os adolescentes com práticas infracionais. Trabalhando no modelo da intervenção focal e considerando o contexto emergencial da situação do acautelamento, os autores sustentam que as intervenções focais permitem o trabalho com a ansiedade e os quadros depressivos. Todavia, o mais interessante é que o material construído a partir da escuta dos adolescentes permitiu concluir que o tema da relação da adolescência com práticas infracionais é complexo e atravessado por questões sociais, familiares, da própria adolescência e econômicas.

Pensando na importância das famílias para o contexto do cumprimento da medida socioeducativa, Costa, Guimarães, Pessina e Sudbrack (2007) nos oferecem a possibilidade do conhecimento da metodologia de avaliação familiar na perspectiva da Single Session Work, que, baseada em uma intervenção única com as famílias dos adolescentes que cumprem medidas de internação, pretende compreender os paradigmas familiares e, assim, gerar informações que possibilitem o resgate dos vínculos parentais. Os autores defendem a potencialidade dessa intervenção e sua grande contribuição para o enfrentamento desse problema social.

Confirmando a importância do ambiente familiar tanto para compreender a vinculação do adolescente com a criminalidade, quanto para viabilizar a intervenção nas medidas socioeducativas, a pesquisa de Lima, Alcântara, Almeida e Alves (2006) revela que "92\% dos adolescentes já haviam experimentado, pelo menos uma vez, algum tipo de violência no ambiente familiar" (p. 20). Foram entrevistados 120 adolescentes que respondem por medidas socioeducativas, abordando-se o tema de experiências de violência intrafamiliar. $\mathrm{O}$ tema crônico da família pode preparar o terreno para pensar nas políticas sociais que contemplam as populações excluídas.

Essa breve apresentação de alguns artigos do plano prático-experiencial não contempla a riqueza dos artigos 
deste eixo, entretanto, permite condensar os seguintes pontos: críticas a uma prática adaptativa da psicologia, aposta na subjetividade como elemento importante na reabilitação, invenção de novas estratégias de intervenção, discussão dos processos de saúde-doença, da adolescência e do lugar do preconceito no trabalho do socioeducativo. Para maiores desdobramentos na análise desses dados, a equipe se dedicou à produção de um artigo específico para contemplar todos os textos deste plano: “Os desafios da aplicação das medidas socioeducativa no Brasil: Uma reflexão sobre diferentes relatos de experiências" (Moreira, Souza, Rocha, Guerra, \& Peixoto, 2014).

\section{Plano Político-Institucional}

A segunda categoria de artigos se centra no tema das políticas. É constituída pelo levantamento e avaliação de medidas jurídicas e institucionais que buscam enfrentar a questão da infração adolescente. $\mathrm{O}$ universo normativo que assim é construído não nasce do puro arbítrio do legislador, dependendo tanto de concepções filosóficas e científicas, nem sempre bem tematizadas e elaboradas, quanto dos movimentos, frequentemente oscilantes, da opinião pública, tomados ambos na interpretação do fato social ilícito legalmente. Encontram-se, nesta categoria, 16 artigos.

Tal é o caso do artigo de Lemos (2009) que, em uma abordagem foucaultiana, analisa o apagamento do processo social e histórico de luta dos movimentos sociais de proteção aos direitos humanos de crianças e adolescentes pelo ato legislador do então Presidente do Brasil, Fernando Collor de Melo, ao assinar a promulgação do ECA. Como ato político que ficou marcado como símbolo da modernização da justiça brasileira, ganha aparência de concessão do Estado, de ato naturalizante e populista, ocultando o jogo de forças políticas e sociais presentes no contexto de fundo que culminou na promulgação da lei.

Também Arantes (2009) critica a noção legal de proteção integral, presente no texto do Estatuto, em face do reconhecimento da capacidade de crianças e adolescentes para o exercício de seus direitos, tensionando a relação proteção-autonomia. Para ela, pensar os direitos humanos de crianças e adolescentes requer o reconhecimento dessa tensão, que não implica necessariamente uma contradição entre pessoa em desenvolvimento e sujeito de direitos, entre proteção e autonomia. Assim, a questão fundamental, para a autora, é a de como entender o sentido da proteção integral a que têm direito crianças e adolescentes sem confundi-la com a proteção dispensada pelo sistema tutelar menorista, vigente no Brasil em quase todo o século XX.

Parece-nos importante ressaltar que, segundo Miraglia (2005), a mudança do termo menor para adolescente ou pessoa em desenvolvimento, e da expressão delinquência para o conceito de ato infracional, visa mudanças no próprio aparato judicial (Miraglia, 2005). Assim, a letra da lei pretende mudar as posições políticas e subjetivas diante desses jovens. Porém, segundo Minahim e Sposato (2011), essas mudanças podem ser interpretadas como uma negação da índole penal das medidas socioeducativas.
Nesse sentido, Mello (1999) e Balaguer (2005) denunciam que, anterior à violência cometida pelos adolescentes autores de ato infracional, o que se verifica é a violência do Estado na privação do acesso desses sujeitos aos seus direitos civis. Omisso em relação às camadas mais pobres da população, o Estado os priva de seus direitos civis mais básicos, colocando-os em uma fronteira para aquém da cidadania. A situação de violência pode ser replicada pela privação de liberdade das medidas. Assim, Aranzedo e Souza (2007) se dedicam ao estudo da vivência da privação de liberdade e planos para o futuro de adolescentes envolvidos em homicídios, discutindo, na perspectiva desses adolescentes, o cotidiano antes da internação, os significados e sentimentos associados à vivência da medida privativa de liberdade e seus planos para o futuro.

Os artigos desta categoria indicam que a política, as leis e as instituições precisam considerar a situação de violência permanente à qual esses jovens são submetidos, articulando o plano institucional ao plano macroestrutural das relações societárias. Assim, parece-nos fundamental compreender os determinantes desse cenário, tema que é objeto de estudo dos artigos da categoria teórico-sociocultural. A discussão mais aprofundada do conjunto de artigos que denominamos como plano político-institucional se encontra em duas publicações da equipe: "A Medida Socioeducativa de Internação Sob uma Lente Foucaultiana" (Moreira, Souza, Rocha, Guerra, \& Peixoto, 2014) e "Medidas socioeducativas com seus dispositivos disciplinares: O que, de fato, está em jogo nesse sistema?" (Moreira, Guerra, Oliveira, Souza, \& Soares, 2015).

\section{Plano Teórico-Sociocultural}

Constituído pelo trabalho de convergência e confronto de hipóteses e teorias acerca da sociedade, da cultura e da modernidade. Trata-se de um plano eminentemente teórico, porque não há como intervir na totalidade social, restando-nos apenas tentar pensá-la de forma a criar um marco epistêmico de análise. No entanto, esse trabalho não é "abstrato" em mau sentido, algo inútil e um puro jogo de ideias, pois lhe cabe uma função dupla: (a) a de crítica da experiência e das medidas institucionais, pois tais hipóteses e teorias, muitas vezes, permanecem subjacentes aos dois outros planos; e (b) a de construção de novas hipóteses e teorias mais elaboradas e consistentes, que deverão ser confrontadas com as experiências e práticas. Encontram-se nesta categoria nove artigos.

Entre eles, destaca-se o trabalho de Vorcaro, Mazzini e Monteiro (2008), que analisam as leituras que determinam a falta do pai concreto como causa do problema da violência juvenil. As autoras defendem a importância da distinção entre ausência do pai concreto e a falha na inscrição do nome do pai. Para as autoras, não é possível afirmar que a ausência do pai concreto é o fator causa da violência entre os adolescentes, porque cada sujeito se posiciona de uma forma singular frente aos acontecimentos da vida.

A relação dos indivíduos com os seus pais, durante a infância,

fornece a estrutura das outras relações que serão estabelecidas ao longo da vida. Entretanto, conforme descreve Lacan (1995) 
em "As relações de objeto", a construção das funções materna e paterna, bem como o efeito destas, não equivale às pessoas que as encarnam, mas refere-se ao que foi transmitido ao sujeito em constituição como ideais referenciais dessas funções. A ausência da figura concreta do pai certamente implicará uma especificidade para a vida dos sujeitos. Isso é sabido e inquestionável. A questão é saber se tal especificidade determinará o cometimento de atos infracionais durante fases posteriores da vida. (p. 136)

É nesse sentido que a teoria psicanalítica discorre sobre a singularidade de cada caso. "Por meio dela, sabe-se que as influências de determinado evento dependerão da forma como o sujeito, a partir de sua história, se apropriará dele" (Vorcaro et al., 2008, p. 136).

Já Moreira, Rosário e Costa (2008) apostam em uma leitura interdisciplinar e, assim, articulam ideias da Sociologia, como os apelos da sociedade de consumo, com conceitos da psicanálise que trabalham o tema da relação euoutro e a violência, bem como com apontamentos filosóficos sobre a pós-modernidade. Fundamentados na articulação entre esses três campos teóricos, os autores consideram que, como símbolo da Pós-Modernidade, toma-se um sujeito na perspectiva narcísica, cujo desejo tem por destino uma "direção marcadamente exibicionista e autocentrada, na qual o horizonte intersubjetivo se encontra esvaziado" (Birman, 1999, p. 24). Trata-se de um momento histórico caracterizado por encontros desprovidos de densidade existencial, vínculos frouxos e sujeitos com baixa capacidade de simbolização. Assim, sua aposta é na palavra. Sabendo-se inviável a existência humana fora das fronteiras do simbólico, tem-se, na busca pela palavra, o único meio de se conter o homem no gozo desenfreado que o conduz à barbárie do real. Desse modo, conforme destacado, é através da escuta que poderão emergir os sujeitos que contemporaneamente se escondem atrás de atos criminosos. Afinal, em razão de se encontrarem no ponto crítico de uma transição histórica, os adolescentes contemporâneos fazem-se arautos de um novo modelo de sociedade. Dessa forma, "por denunciarem a falência de antigos valores, seus sintomas podem ser a chave de um novo tempo, regulado por novas ideias, que as ultrapassadas lentes da Modernidade nos andam impedindo de enxergar" (p. 1.044).

Guerra et al. (2010), seguindo a trilha que articula a violência juvenil com as características da contemporaneidade e apostando no tratamento interdisciplinar para o tema, pensam como o hedonismo, o imediatismo, a fragilidade dos laços sociais e o consumismo podem ser ingredientes que contribuem para o enlaçamento dos jovens de grandes aglomerados com a criminalidade. As autoras revelam que a relação dos jovens com a criminalidade deve levar em conta a realidade psíquica e entender o sujeito como ser conectado a seu espaço geográfico local e a seu tempo histórico mundial.

Como se pode notar, nesta categoria se evidenciam os determinantes sociais implicados na produção do discurso sobre o adolescente infrator, bem como a dimensão psíquica de sua atuação. Pontos destacados que auxiliam à compreensão do jovem e da estrutura societária na qual ele se insere. Essa breve discussão sobre os artigos que compõe o plano teórico-sociocultural se encontra na sua forma expandida no artigo "Recognition and Indeterminacy:
A Psychoanalytic Reading of Illegals Acts in Adolescence" (Moreira, Guerra, Martins, Cadar, \& Rosário, 2015)

Cabe explicitar que esses três planos estão dialeticamente interligados: não só no sentido ascendente da abstração, mas também no sentido descendente da concreção. No primeiro sentido, parece haver uma crescente explicitação e clarificação das ideias e, no segundo sentido, o que foi explicitado e clarificado se choca inevitavelmente com a opacidade do real.

\section{Considerações Finais}

Marcadamente interdisciplinar, o périplo discursivo e científico da produção acadêmica brasileira sobre as medidas socioeducativas, que problematiza a relação entre adolescência, criminalidade e medidas socioeducativas, revela o esforço de trabalho reflexivo nacional desse setor público. A prevalência da análise de experiências concretas parece refletir um empenho de sistematização e sofisticação na interpretação e operacionalização da legislação, parecendo fundar um plano político crítico na ação cotidiana.

Esse primeiro plano é seguido numericamente das análises no plano político-institucional. Nestas, a análise das ações táticas operacionalizadas na rotina institucional são substituídas por reflexões que buscam discutir a lógica intrínseca na proposição e na gestão das políticas públicas do setor das medidas socioeducativas no Brasil. Dessa maneira, localiza os impasses lógicos que sustentam os paroxismos da prática, explicitando as contradições entre o ideal social - refletido no plano político e jurídico - e a realidade factual da abordagem dos jovens em conflito com a lei, com sua multiplicidade de respostas, nem todas apreensíveis pelo normativo regulador de nossas regras de boa convivência.

Finalmente, os artigos teóricos do plano sociocultural buscam elucidar, em uma posição extrínseca à política socioeducativa nacional, seus pontos estruturais de orientação e sustentação, buscando analisar a reflexividade discursiva de nosso tempo sobre as diferentes modalidades de gestão dos corpos e dos afetos adolescentes em nosso tempo histórico. Também analisam estruturalmente as subjetividades aí em jogo, lançando um olhar sobre o adolescente que transcende sua condição apenas histórica e permitindo a concatenação de nosso tempo, nossa história, com seus modos de gestão da vida e da experiência idiossincrática da adolescência, compondo análises estruturais dos processos culturais, políticos e subjetivos envolvidos nas medidas socioeducativas. Esses textos contribuem, assim, para a consolidação de uma visada estrutural acerca dos modelos que adotamos para tentar garantir o bem comum e o normal social.

Assim, após 25 anos de promulgação do ECA e quatro do SINASE, verificamos que os avanços do campo ainda são pequenos face ao discurso de criminalização da pobreza e à mortalidade juvenil. Apesar do exercício cotidiano de reflexão crítica e revisão da atuação no campo socioeducativo, ainda se observam dados de mortalidade inaceitáveis, como visto no início desse artigo, e retrocessos imperdoáveis, como o da Proposta de Emenda Constitucional PEC n ${ }^{\circ}$ 171/193, que propôs a alteração da redação do artigo 228 da Constituição 
Federal, para reduzir de 18 para 16 anos a maioridade penal para os casos de infrações equivalentes a crimes hediondos.

Dessa maneira, vemos como o tempo atual, em sua urgência, e o pragmatismo, em seu anseio de eficiência e efetividade, acabam por enquadrar certo discurso, inclusive científico, acerca de modelos ideais e normativos de vida. A produção acadêmica sobre as medidas socioeducativas aqui analisada evidencia modos de resistência, mas também de cessão, a essa pressão de nosso tempo, demarcando sinais de que, em face de um fato histórico complexo e atual, ainda podemos apostar em soluções que não se rendam ao lugar comum e à reincidência das instituições no mesmo. Por outro lado, a análise dessa produção adverte para o fato de que o trabalho apenas se esboça, ainda não tendo encontrado uma boa medida para lidar com essa manifestação de nosso mal-estar, talvez porque ele seja irredutível a qualquer forma de gestão e controle. Essa análise, assim, oferece-se como ponto propulsor de novas reflexões, sistematizando o campo discursivo já existente.

\section{Referências}

*Almeida, M. M. de., \& Silva, R. C. da. (2004). Compreendendo as estratégias de sobrevivência de jovens antes e depois da internação na FEBEM. Revista Brasileira de Orientação Profissional, 5(1), 82-102.

*Alves, C., Pedroza, R., Pinho, A., Presotti, L., \& Silva, F. (2009). Adolescência e maioridade penal: Reflexões a partir da psicologia e do direito. Revista Psicologia Política, 9(17), 67-83.

*Arantes, E. M. de M. (2009). Proteção integral à criança e ao adolescente: Proteção versus autonomia? Psicologia Clínica, 21(2), 431-450.

*Balaguer, G. (2005). Violência e adolescência: Uma experiência com adolescentes internos da FEBEM/SP. Imaginario, 11(11), 91-109.

*Barra, M. B. (2007). A clínica psicanalítica em um ambulatório para adolescentes em conflito com a lei. Estudos e Pesquisas em Psicologia, 7(3) 72-81.

*Bello, L. M. (2001). Jovens infratores e a terapia: Uma questão para os "observadores da multiplicidade humana". Psicologia, Ciência e Profissão, 21(4), 34-43. doi: http://dx.doi. org/10.1590/S1414-989320 01000400005.

Birman, J. (1999). Mal-estar na atualidade. Rio de Janeiro: Civilização Brasileira.

Brasil. (1990). Lei Federal no 8.069, de 13 de julho de 1990. Estatuto da criança e do adolescente (ECA). Recuperado em 01 março 2014 de http://www.planalto.gov.br/ccivil/LEIS /L8069.htm.

Brasil. (2012). Lei Federal $n^{\circ}$ 12.594, de 18 de Janeiro de 2012. Sistema Nacional de Atendimento Socioeducativo (SINASE). Recuperado em 21 de fevereiro de 2014 de http://www. planalto.gov.br / ccivil_03 /_ato2011-2014/2012/lei/112594. htm.

*Brito, L. M. T. de. (2007). Liberdade assistida no horizonte da doutrina de proteção integral. Psicologia, Teoria e Pesquisa, 23(2), 133-138. doi: http://dx.doi.org/10.1590/S010237722007000200003 .
*Cella, S. M., \& Camargo, D. M. P. (2009). Trabalho pedagógico com adolescentes em conflito com a lei: Feições da exclusão/ inclusão. Educação \& Sociedade, 30(106), 281-299.

*Costa, C. B., \& Almeida, E. O. C. de. (2007). Violência: A compreensão do conceito por jovens submetidos a medidas socioeducativas. Psicologia Revista da Vetor Editora, 8(1), 71-76.

*Costa, C. R. B. S. F. da. (2005). É possível construir novos caminhos? Da necessidade de ampliação do olhar na busca de experiências bem-sucedidas no contexto sócio-educativo. Estudos e Pesquisa em Psicologia, 5(2), 79-95.

*Costa, C. R. B. S. F. da., \& Assis, S. G. de. (2006). Fatores protetivos a adolescentes em conflito com a lei no contexto socioeducativo. Psicologia \& Sociedade, 18(3), 74-81. doi: http://dx.doi.org/10.1590/S0102-71822006000300011.

*Costa, L. S. da, Carvalho, M.C. N., \& Wentzel, T. R. (2009). Intervenção psicológica focal em adolescentes autores de ato infracional. Ciência \& Cognição, 14(2),130-146.

*Costa, L. F., Guimarães, F. L., Pessina, L. M., \& Sudbrack, M. F.O. (2007). Single session work: Intervenção única com a família e adolescente em conflito com a lei. Revista Brasileira de Crescimento e Desenvolvimento Humano, 17(3), 104-113.

*Costa, L., Penso, M. A., Sudbrack, M. F. O., \& Jacobina, O. M. P. (2011). Adolescentes em conflito com a lei: O relatório psicossocial como ferramenta para promoção do desenvolvimento. Psicologia em Estudo, 16(3),379-387.

*Coutinho, M. da P. de L.,Estevam, I. D.,Araujo, L.F., \& Araujo, L. S. (2011). Prática de privação de liberdade em adolescentes: Um enfoque psicossociológico. Psicologia em Estudo, 16(1), 101-109. doi: http://dx.doi.org/10.1590/S141373722011000100012 .

*Gallo, A. E. (2008). Atuação do psicólogo com adolescentes em conflito com a lei: A experiência do Canadá. Psicologia em Estudo, 13(2), 327-334. Recuperado de http://www. scielo.br/scielo.php?script=sci_arttext\&pid=S1413$73722008000200015 \& \operatorname{lng}=$ pt\&tlng=pt.

*Germano, I., \& Bessa, L. L. (2010). Pesquisas narrativo-dialógicas no contexto de conflito com a lei: Considerações sobre uma entrevista com jovem autora de infração. Revista Mal-Estar e Subjetividade, 10(3), 995-1033.

Gomes, R. (2001). A análise de dados em pesquisa qualitativa. In M. C. S. Minayo (Ed.), Pesquisa social: Teoria, método e criatividade (pp. 67-80). Petrópolis: Vozes.

*Guerra, A. M. C., Moreira, J. O., Lima, N. L., Pompeo, B. D. S., Soares, C. A. N., Carvalho, L. M. S., \& Pechir, N. A. N. (2010). Construindo ideias sobre a juventude envolvida com a criminalidade violenta. Estudos e Pesquisas em Psicologia, 10(2), 434-456.

*Jacobina, O. M. P., \& Costa, L. F. (2007). Para não ser bandido: Trabalho e adolescentes em conflito com a lei. Cadernos de Psicologia Social do Trabalho, 10(2), 95-110.

*Jost, M. C. (2010). Fenomenologia das motivações do adolescente em conflito com a lei. Psicologia: Teoria e Pesquisa, 26(1), 99-108. doi: http://dx.doi.org/10.1590/S010237722010000100012.

*Kobayashi, M. do C. M., \& Zane, V. C. (2010). Adolescente em conflito com a lei e sua noção de regras no jogo de futsal. Revista Brasileira de Educação Física e Esporte, 24(2), 195-204. doi: http://dx.doi.org/10.1590/S 1807-55092010000200004. 
Lacan, J. (1995). O Seminário, livro 4: A relação de objeto (195657). Rio de Janeiro: Jorge Zahar. (Original publicado em 1956-57)

Laville, C., \& Dionne, J. (1999). A construção do saber: Manual de metodologia da pesquisa em ciências humanas. Porto Alegre: Artmed.

*Lemos, F. C. S. (2009). O Estatuto da Criança e do Adolescente em discursos autoritários. Fractal Revista de Psicologia, 21(1), 137-150.

*Lima, I. M. S. O. Alcântara, M. A. R., Almeida, K.V. D., \& Alves V. S. (2006). Experiências de violência intrafamiliar entre adolescentes em conflito com a lei. Revista Brasileira de Crescimento e Desenvolvimento Humano, 16(2), 16-24.

* López, E. G. (2004). Edad penal y psicología jurídica: la necesidad de una respuesta social al adolescente infractor. Psicologia para América Latina, 2. Recuperado de http://pepsic.bvsalud.org/ scielo.php?script=sci_arttext\&pid=S1870-350X2004000200 $002 \& \operatorname{lng}=\mathrm{pt} \& \mathrm{t} \operatorname{lng}=\mathrm{es}$.

*Mello, S. L. de. (1999). Estatuto da criança e do adolescente: É possível torná-lo uma realidade psicológica? Psicologia, 10(2), 139-151.

*Menicucci, C. G., \& Carneiro, C. B. L. (2011). Entre monstros e vítimas: A coerção e a socialização no Sistema Socioeducativo de Minas Gerais. Serviço Social \& Sociedade, 107, 535-556. doi: http://dx.doi.org/10.1590/S0101-66282011000300009.

*Minahim, M. A., \& Sposato, K. B. (2011). A internação de adolescentes pela lente dos tribunais. Revista Direito GV, 7(1), 277-298. doi: http://dx.doi.org/10.1590/S180824322011000100014.

* Miraglia, P. (2005). Aprendendo a lição: Uma etnografia das Varas Especiais da Infância e da Juventude. Novos Estudos, CEBRAP, 72, 79-98. doi: http://dx.doi.org/10.1590/S010133002005000200005.

*Monte, F. F. de C., Sampaio, L. R., Rosa Filho, J. S., \& Barbosa, L. S. (2011). Adolescentes autores de atos infracionais: Psicologia moral e legislação. Psicologia \& Sociedade, 23(1), 125-134. doi: http://dx.doi.org/10.1590/S0102-71822011000100014.

*Monteiro, L. de O. (2006). A judicializaçao dos conflitos de adolescentes infratores: Solução ou mito? Revista Katálysis, 9(1), 63-74.

*Moreira, J. O., Rosario, Â. B. do., \& Costa, D. B. da. (2008). Criminalidade juvenil no Brasil pós-moderno: Algumas reflexões psicossociológicas sobre o fenômeno da violência. Revista Mal-Estar e Subjetividade, 8(4), 1021-1046.

Minayo, M. C. de S. (2001). Ciência técnica e arte: O desafio da pesquisa social. In M. C. S. Mynaio (Ed.), Pesquisa social: teoria, método e criatividade (pp. 9-30). Petrópolis: Vozes.

Moreira, J. O., Romagnoli, R. C., Rocha, P. M., Dias, A. F. G., \& Bouzada, G. C. F. A. (2014). Medida socioeducativa de internação sob uma lente foucaultiana. Polis e Psique, 4, 7389. Retirado de http://seer.ufrgs.br/index.php/PolisePsique/ article/view/46017.

Moreira, J. O., Guerra, A. M. C., Oliveira, N. A., Souza, J. M. P., Soares, C. A. N. (2015). Medidas socioeducativas com seus dispositivos disciplinares: O que, de fato, está em jogo nesse sistema? Revista Psicologia Política, 15(33), 285-302.
Moreira, J. O., Guerra, A. M. C., Martins, A. S., Cadar, A. C. B., \& Rosário, A. B. (2015). Recognition and Indeterminacy: A psychoanalytic reading of illegals acts in adolescence. Psychology (Irvine), 06, 1570-1579. doi: http://dx.doi. org/10.4236/psych.2015.612154.

Moreira, J. O., Souza, J. M. P., Rocha, P. M., Guerra, A. M. C., Peixoto, M. L. V. L. (2014). Os desafios da aplicação das medidas socioeducativa no Brasil: Uma reflexão sobre diferentes relatos de experiências. Psychologia Latina, 5, 1-10. Retirado de http://pendientedemigracion.ucm.es/info/ psyhisp/es/8/art35.pdf.

*Nascimento, M. L. do, Lacaz, A. S., \& Travassos, M. (2010). Descompassos entre a lei e o cotidiano nos abrigos: Percursos do ECA. Aletheia, 31, 16-25.

*Passamani, M. E., \& Rosa, E. M. (2009). Conhecendo um programa de liberdade assistida pela percepção de seus operadores. Psicologia, Ciência \& Profissão, 29(2), 330-345.

*Penso, M. A., \& Sudbrack, M. de F. O. (2009). O filho fora do tempo: Atos infracionais, uso de drogas e construção identitária. Arquivo Brasileiro de Psicologia, 61(1), 2-15.

*Perfeito, D. M. (2005). Adolescentes infratores: Uma aprendizagem e uma luz na psicoterapia - relato de prática profissional. Psicologia para América Latina, 4. Recuperado de http:// pepsic.bvsalud.org/scielo.php?script=sci_arttext\&pid=S1870350X2005000200007\&lng=pt\&tlng=pt..

*Rosario, Â. B. do. (2010). Grupo com adolescentes em privação de liberdade: Circulação da palavra como possibilidade de ressignificação do ato infracional. Revista SPAGESP, 11(1), 66-76.

*Rosário, A. B. (2004). O mundo do crime: Possibilidade de intervenção a adolescentes em conflito com a lei. Mental, 2(2), 101-113. Recuperado de http://pepsic.bvsalud.org/scielo. php?script $=$ sci_arttext\&pid=S1679-44272004000100008\&ln $\mathrm{g}=\mathrm{pt} \& \mathrm{tlng}=\mathrm{pt}$.

Roudinesco, E. (2006). A análise e o arquivo. Rio de Janeiro: Jorge Zahar.

Santos, B. de S. (2001). Da ideia de universidade à universidade da ideia. In Pela Mão de Alice O social e o político na transição pós-moderna (pp. 163-202). $8^{\circ}$ edição. São Paulo: Cortez

*Santos, T. C. dos, \& Zeitoune, C. da M. (2011). Amor, impasses da sexuação e ato infracional na adolescência. Tempo Psicanalítico, 43(1), 85-108.

*Sartorio, A. T., \& Rosa, E. M. (2010). Novos paradigmas e velhos discursos: Analisando processos de adolescentes em conflito com a lei. Serviço Social e Sociedade, 103, 554-575.

*Silva, A. A., Lemos, F. C. S., \& Mello, R. P. (2011). Percursos de um jovem pela rede jurídica: Uma análise crítica. Barbaroi, $35,58-74$.

*Silva, F. S., Oliveira, F. H. da S., Piccione, M. A., \& Lemos, R. F. (2008). Futebol libertário: Compromisso social na medida. Psicologia, Ciência \& Profissão, 28(4), 832-845.

*Silva, I. R. de O., \& Salles, L. M. F. (2011). Adolescente em liberdade assistida e a escola. Estudos de Psicologia, 28(3), 353-362. doi: http://dx.doi.org/10.1590/S0103166X2011000300007.

*Silva, R. de A. (2007). As múltiplas faces da violência. Latin American Journal of Fundamental Psychopathology, 4(2), 219-228. 
*Silveira, A. D. (2012). Atuação do Tribunal de Justiça de São Paulo com relação ao direito de crianças e adolescentes à educação. Revista Brasileira de Educação, 17(50), 353-368.

*Silveira, K. S. S., Machado, J. C., Zappe, J. G., \& Dias, A. C. G.. (2015). Projetos futuros de adolescentes privados de liberdade: implicações para o processo socioeducativo. Psicologia: Teoria e Prática, 17(2), 52-63. Recuperado de http://pepsic. bvsalud.org/scielo.php?script=sci_arttext\&pid=S151636872015000200004\&lng=pt\&tlng=pt.

*Sisto, F. F., Cecilio-Fernandes, D., \& Silveira, F. J. (2012). Funcionamento diferencial de condutas agressivas em jovens infratores e universitários agressivos. Estudos e Pesquisa em Psicologia, 12(1), 158-174.
*Spagnol, A. S. (2005). Jovens delinqüentes paulistanos. Tempo \& Sociedade, 17(2), 275-299.

*Vicentin, M. C. G., Gramkow, G., \& Rosa, M. D. (2010). A patologização do jovem autor de ato infracional e a emergência de "novos" manicômios judiciários. Revista Brasileira de Crescimento \& Desenvolvimento Humano, 20(1), 61-69.

*Vorcaro, Â., Mazzini, C. de A., \& Monteiro, J. P. (2008). Ato infracional e metáfora paterna. Psicologia Teoria e Prática, 10(2), 135-146.

Waiselfisz, J. J. (2012). Mapa da violência no Brasil: 2010. Anatomia dos Homicídios no Brasil . São Paulo: Instituto Sangari. Recuperado de http://www.mapadaviolencia.org.br/pdf2010/ MapaViolencia2010.pdf

*Zappe, J. G., \& Ramos, N. V. (2010). Perfil de adolescentes privados de liberdade em Santa Maria/RS. Psicologia \& Sociedade, 22(2), 365-373. 